\title{
The experience of design students during an international project cooperation
}

\author{
A experiência de alunos de design durante um projeto de cooperação \\ internacional
}

Cecília Eloy Neves, Fábio Ferreira da Costa Campos, Guilherme Daguir e Walter Franklin.

\author{
User experience, design methods, techniques for alternative generation and selection, design \\ methodology.
}

The present research aims to analyze the experience of design students cooperating in an international design team to solve a common problem. The Bachelor Course of Design at the Federal University of Pernambuco (UFPE) offered to its students a new opportunity to have an international experience without leaving Recife. During the first semester of 2019, UFPE started to test a new kind of internationalization called COIL (Collaborative Online International Learning) which aims to give international experience to the students. With COIL the students participate in collaborative activities in partnership with foreign universities. Based on this model, we used one of the disciplines from the Design bachelor course, Techniques for Alternative Generation and Selection (TGSA) and altered it to allow our students make activities in partnership with the students from two other universities, the Breda University of Applied Sciences (BUAS) in the Netherlands and The State University of New York (SUNY) in the United States of America. Therefore, the students were divided into multinational groups, to use design methods learned in class and show up with a solution for a given problem, this problem/question was chosen by the professors from all three universities and was "plastic pollution". The number of students from each country was: 28 from Brazil, 18 from the United States and 10 from the Netherlands. The students were divided into groups, being a total of 8 groups. Each group should contain Americans, Dutch, and Brazilians. For the graduation's students at the Federal University of Pernambuco, the challenge was not only the English language but also how to teach, organize the process and convince the international students to use some method of design to develop a solution for the problem. With this research, we observed both the student's experience and the differences between the methodology in Brazil, Netherlands and the United States of America used during the creative process. Furthermore, was applied a questionnaire with the students where they evaluated how the experience was perceived by them. As a result, we identified differences between the design methodology applied to those universities and evaluate the student's experience during the subject.

\section{Introduction}

In order to offer its students an international experience, in which they could participate in international collaboration groups during classes, the Federal University of Pernambuco (UFPE) is experimenting with a kind of method named "COIL" (Collaborative Online International Learning) which aims to give an international experience to the students in partnership with foreign universities. With this scenario, the discipline Techniques for Alternative Generation and Selection (TGSA), in the Bachelor Program of Design, was remade to have activities with two other universities, the Breda University of Applied Sciences (BUAS) in the Netherlands and The State University of New York (SUNY) in the United States of America.

The discipline TGSA aims to present to students some techniques of design, such as focus group and brainwriting, in other to improve their methodology of design. The semester started, in UFPE, introducing the SPRINT techniques to the Brazilian students. SPRINT has become very popular. It's, basically, a meeting with people that work at the same project to promote more focused project development. With expository and practical lectures, the SPRINT was taught to the Brazilian students. With some methodology background, the UFPE students were guided to introduce that design methodology to the international students, in other to

\section{Anais do 9 $\mathrm{CIDI}$ e 9ㅇ CONGIC}

Luciane Maria Fadel, Carla Spinillo, Anderson Horta, Cristina Portugal (orgs.)

Sociedade Brasileira de Design da Informação - SBDI Belo Horizonte | Brasil | 2019

ISBN 978-85-212-1728-2
Proceedings of the 9th CIDI and 9th CONGIC

Luciane Maria Fadel, Carla Spinillo, Anderson Horta, Cristina Portugal (orgs.)

Sociedade Brasileira de Design da Informação - SBDI Belo Horizonte | Brazil | 2019

ISBN 978-85-212-1728-2 
organize the process. Each international group had to come up with a solution for some problem, the issue recommended by the professor from all three universities was plastic pollution, but the groups could show up with another issue.

Those international groups focused on developing an artifact using design techniques and methods. But the different way of teaching the creative design process was a challenge. During the undergraduate course at UFPE, students go through disciplines that present a methodology of design, involving techniques and methods that help in the design process. That said, the Brazilian students already had a theoretical background on design methodology, before even beginning the subject. What is different in the two other universities, which do not teach students a design methodology, but focus on the result. The courses at BUAS and SUNY are more focused on social media and graphic works, where the main concern is the aesthetics of work than the development process.

With this scenario, this study aims to observe the Brazilian students experience and the differences between the methodology in Brazil, Netherlands and the United States of America used in the creative process. For the graduation's students at the Federal University of Pernambuco, the challenge will not be only the English language, but also how they will teach, organize the process and convince the international's students to use some method of design to develop a solution for the problem. So, for this research, we will have, as a result, the point of view of Brazilian students about the INT subject, the positive and negative points in other to improve to the next classes. And the differences between the methodology in Brazil, Netherlands and the United States of America used in the creative process.

\section{Methodology}

The activities described in this article were spent in a class consisting only of designers, between junior and senior levels. The students are from three countries, a total of 28 from Brazil, 18 from the United States and 10 from the Netherlands. The students were divided into groups, being a total of 8 groups. Each group should contain Americans, Dutch, and Brazilians. No separate groups by gender, or age, groups were organized following the alphabetical order of their names.

All Brazilians had already presented the design methodological structure (LOBACH, 1969), design thinking (GAVIN, AMBROSE, 2016), the Sprint design method (KNAPP, 2016) and carried out projects applying adaptations of these processes. Different for the international students who don't show any background about techniques and methods of design methodology. Design methods and techniques have been showing their importance in numerous researches and daily uses in projects. It is not only limited to data surveys about the user in relation to the artifact, but they are also facilitators for a conversation to take place. Where such interaction between stakeholders, team members, customers, and the users helps designers to have the right conversation at the right time. And, in this way, to develop better and meaningful artifacts (HANINGTON; MARTIN, 2012).

Sprint's concepts would be that of a more practical and continuous process of five days in total, which attempts to solve issues through prototyping and testing ideas with customers (or potential customers). On Monday, the first day of execution of the process, maps the problem and chooses where to focus. On the outline, solutions are outlined on paper. In the fourth design, decisions are made, and ideas are rewritten as hypotheses that can be tested. In the fifth, build a realistic prototype. On Friday the prototype will be used in a test with humans (KNAPP, 2016).

The groups in the Netherlands and the United States had sympathy for other procedural models of design, which did not take into account a linear design, but used some methodological tools such as analysis of similar, mental maps, mood boards, and individual repertoire to arrive at decisions about the artifact to be created. It is worth remembering that 
both universities (BUAS and SUNY) had a focus on results, oriented to the printing industry, while Brazilian students did not have this inclination.

The interaction time between all students was 5 weeks. Being the first week focused in exchange of conversations without the obligation of deliveries in relation project. From the second week on, students reviewed the concepts of processes and tools that they should follow in the coming weeks, with a seven-day delivery of results. The second week of the interaction would result in the exploration of the problem, the third week would result in the generation of alternatives, the fourth week in the selection of the alternative, and the last week a prototype of low fidelity.

The design method used is an adaptation of Knapp's Sprint, with the macro phases being similar but the execution time extended from one day to one week. In addition, different Sprint method design tools were introduced to Brazilian students so that they could expand results in each of the phases. The tools were taught from the foreign literature of Hanington and Martin (HANINGTON, MARTIN, 2012) added to Pazmino (PAZMINO, 2015). More information about the tools in Table 1.

Table 1 - Sprint Phases per week

\begin{tabular}{|c|c|c|c|c|c|}
\hline $\begin{array}{l}\text { Elapsed } \\
\text { time }\end{array}$ & Week 1 & Week 2 & Week 3 & Week 4 & Week 5 \\
\hline Design Step & Ice Breaking & $\begin{array}{l}\text { Phase } 1 \text { - Exploring } \\
\text { the problem }\end{array}$ & $\begin{array}{l}\text { Phase } 2 \text { - } \\
\text { Generation of } \\
\text { alternatives }\end{array}$ & $\begin{array}{l}\text { Phase } 3 \text { - } \\
\text { Selection of the } \\
\text { alternative }\end{array}$ & $\begin{array}{l}\text { Phase } 4 \text { - } \\
\text { Prototyping }\end{array}$ \\
\hline $\begin{array}{l}\text { Tools taught } \\
\text { and } \\
\text { suggested }\end{array}$ & $\begin{array}{l}\text { Video call } \\
\text { with all } \\
\text { students (1 } \\
\text { per time have } \\
\text { had } \\
\text { presented } \\
\text { yourself) }\end{array}$ & $\begin{array}{l}\text { Matrix KQH, } \\
\text { Survey, } \\
\text { Benchmarking, } \\
\text { Mood Board, } \\
\text { Empathy Map, } \\
\text { Focus group. }\end{array}$ & $\begin{array}{l}\text { Crazy } 8, \\
\text { Brainwritting } \\
(6-3-5) .\end{array}$ & $\begin{array}{l}\text { Storymapping, } \\
\text { Criteria points }\end{array}$ & $\begin{array}{l}\text { Paper ou } \\
\text { Digital } \\
\text { Mockups, } \\
\text { Wizard of Oz, }\end{array}$ \\
\hline
\end{tabular}

All participants were encouraged to look for other tools to apply in their projects, but none of them did. All groups had weekly reunion and mentorship.

Finally, the group members were taught to divide the activities of the week applying agile methodologies concepts, and subdividing each tool as a micro step to be accomplished that week, that is, applying the concept of backlog (SUTHERLAND; SUTHERLAND, 2014).

In the end of each sprint phase, the students sent their weekly progress attached to their comments. The final sprint they had the opportunity to present the prototyped work and get feedback for all students in class either mentors. The results were very interesting, some of those results are presented in Table 2.

Table 2 - Group Solutions

\begin{tabular}{l|l|l|l|l} 
Name & Nulla & Alter & Plastic machine & RA glasses \\
\hline Description & $\begin{array}{l}\text { Nulla's mission is to } \\
\text { prevent the } \\
\text { consumption of } \\
\text { singleúse plastics } \\
\text { with weekly }\end{array}$ & $\begin{array}{l}\text { App to teach the } \\
\text { user how to } \\
\text { recycle. Giving } \\
\text { some tips and } \\
\text { information. }\end{array}$ & $\begin{array}{l}\text { Plastic collection } \\
\text { machine, where the user } \\
\text { receives in exchange } \\
\text { tickets for public } \\
\text { transportation, cinemas }\end{array}$ & $\begin{array}{l}\text { For deaf people } \\
\text { to watch movies. } \\
\text { Where, when } \\
\text { putting on the } \\
\text { glasses, a doll }\end{array}$
\end{tabular}


After the experience with foreign students, Brazilian students received a printed questionnaire with 9 questions to evaluate the discipline, interaction with foreign students and the experience, a total of 21 answers. (Table 2 - Printed questionnaire)

Table 3 - Printed questionnaire

\section{Questions:}

1. In general, describe the impact of the partnership with the outside group.

2. How to assess the language of interaction with colleagues from abroad? Was it helpful? Was difficult? Do you think you had any benefits in terms of language development?

3. Was your interculturality influenced?

4. Has your knowledge in curricular terms been influenced?

5. Describe the main strengths of the partnership.

6. Describe the main negatives of the partnership.

7. What do you think of synchronous dating? Are important? How many do you value being interesting throughout the partnership?

8. What is your impression in terms of the technological tools used for the partnership (Blackboard, Moodle, Google, Facebook, other ...)?

9. Was it worth it? Would you participate in a COIL (BRAVE) methodology again? Because?

According to the answers to the first question, it was possible to understand that the students found this interaction with foreigners very interesting and useful. Where it was possible to see the differences in the creative process and how different cultures interfere in the process and in the solution of the problem. But it is also important to point out that the difficulty of engaging some foreign students and the difficulty of communication interfered in the process of some groups.

About the second question, it is possible to affirm the students did not consider the English language an obstacle, but an opportunity to improve their knowledge of the language. Those who already had knowledge of the language could put into practice. While those who did not have, 1 or 2 students, found an interest experience but did not add much since they depended on the other group members to communicate with foreigners. In the third question, 12 answered yes, 2 said that their interculturality was influenced a little and the others said no. In this way, although some groups have had problems in organizing the design process in a way that all interact, either by lack of communication generated by the time zone or by the lack of engagement of some students, the interaction between students Brazilian and international levels was very significant.

The fourth question asked about the knowledge, the students were divided between the yes and the no. The affirmations varied, of the students who affirmed that they did not have, during the subject, a curricular addition, they said that nothing new was presented during the discipline or that they did not acquire any new knowledge of the foreign students. Since the Brazilian students were the ones who taught. Among this affirmations, some others said that they acquired new knowledge during the subject and that it was very enriching to be able to 
apply the methodology that already knew in practice. In the fifth, the answers were: Exchange of different current perspectives on the same subject; Development of learning from another language; Sharing of different methodologies; Contact with foreigners; Understand how the design process works in other countries; Knowledge Exchange; Culture exchange; Learning how to adapt to defending skills and cultures; Network; New references; People management; In-depth study of design methods; Exchange of experiences; Simulation of the reality of work with multicultural teams; Know how they deal with academic work; Acquire the ability to adapt methodologies; Teach something; Deal with adversities of the distance partnership. The greatest gain of the Brazilians with this interaction was the exchange of knowledge and cultures, besides the possibility to extend the knowledge of the English language.

About the negative points, the responses were: Lack of engagement; Communication problems; The delay to do the job; Little commitment to deadlines; Lack of a general structure for both sides of the group; Difficulty meeting appointments; Misalignment between what was charged there and here; Different expectations for the project; Stressful process; Lack of interest on the part of foreigners; Short interaction time; Not very good results; Little openness of American students; Resistance of foreigners to use the Brazilian methodology; The tongue. But always revolving around the lack of engagement and interest of foreigners to the work and methodology of Brazilians and the difficulty of communication because of the time zone and even the language.

All Brazilian students agree that synchronous meetings between members of the same project are important, but a few had the opportunity to have such meetings during the process. Whether due to time zone or lack of interest. Some students agreed that one meeting per week would be very good, while others said that depended on the project. Even without such meetings, most groups were able to finalize the project without much difficulty, through text messages. The lack of communication was a problem very much raised by the students and that maybe should be rethought for the other disciplines, as well as an alignment between the Brazilian and foreign disciplines when it comes to methodology. Most groups were limited to using Google Drive and Docs to share and edit files, and Telegram to communicate. They complained a bit about the Hangout connection difficulty. In general, none of the tools were new to them and they had no difficulty in using them. The tools were very used during the process and indispensable to advance the project. Of the 21 answers, 16 said that they would do another subject with the COIL methodology, they liked the contact with foreigners and the acquired results. Only 3 students said that they might return to a COIL discipline, due to the negative points mentioned above. 2 students said that they would not go back because they did not like the experience and did not get the foreign students to collaborate. Overall, was a positive experience for the Brazilian students.

\section{Discussion}

Several topics were revealed from this virtual exchange. Many topics are reportage remarks and confirm design trends and project education methods worldwide. Other topics discussed here are questions directly pointed out by the participating students, through personal mentoring.

The first question is methodological differences. Dutch and American students have found it difficult to adapt to agile methodologies such as sprint (KNAPP, 2016). These students from Europe and North America reported and demonstrated prior to the very first meeting their adoption and dedication to repertoire-based methodologies. Being the procedural order, in the first definition of the problem, according to the search for similar, competitors or inspirations, as third stage the creation and optimization.

Although the purpose of the course was agreed upon in order for students to learn other methods of design, it was disruptive for these students to approach codesign and research prior to and subsequently with users and/or target audience of the designed artifact. This discipline

Anais do 9ํㅡㄹ Congresso Internacional de Design da Informação | CIDI 2019 
has tried to simulate and stimulate the projection involving real-life issues. By tilting students to gain more theoretical knowledge and apply it in a practical way, transforming the discipline into a design with market product potential. This is a World trend punctuated by Thoring, Desmet and Badke in recent studies on creative environments and design schools (THORING, DESMET, BANDKE-SCHAUB, 2018).

This connection with the real problems that occur in the three countries stimulated the designers to have a level of engagement and empathy for the problem that positively affected the quality of the projects elaborated during the 4 weeks. The projects were delivered as prototypes or proof of concept but had focus and design detail to be implemented as real products. All projects involved digital artifacts on some level. Three projects used technology but with the greatest benefit and action taking place in the physical world. All six other projects involved fully digital solutions.

The fact is, the students were free since beginning to produce any kind of solution. However it is added here two hypotheses, the first is that this result was influenced by the students' age, the second is because this result was influenced by the contemporary issue of the excessive use of digital technologies in human routine. Research is recommended for later validation of these possibilities.

While students were committed to maintaining active communication, virtual management was a challenge for all. Weekly, all groups had the mission of holding a virtual meeting (video or text) and defining a part of the project that would occur sequentially and linearly. Through their reports and in-room discussions, Latino students hoped for a long-term presence and interactions with social interaction. On the other hand, the North ones were more interested in continuing the project in an objective way.

Meetings were held over the weeks between group members, online and instant messaging, combined with weekly advice, and deliveries on mixed dates. Although these events were completed, the students finished the course by identifying the whole experience with an organizational gap, especially in relation to other universities. It is worth investigating in similar future activities the motivations and impact of this feeling.

It is recommended to search for procedural tools for similar situations. International cooperation is in the process of popularization and it is possible that the sides may have operational diversities, converged through methods that envisage this interconnection. These tools can impact digital nomads, which are already a reality in interdisciplinary activities that may involve designers.

Meetings were held over the weeks between group members, online and instant messaging, combined with weekly advice, and deliveries on mixed dates. Although these events were completed, the students finished the course by identifying the whole experience with an organizational gap, especially in relation to other universities. It is worth investigating in similar future activities the motivations and impact of this feeling.

\section{Conclusion}

The content of this article provides details of a specific case, which collaborate on issues involving the teaching, method, and activity of the designer. This article reveals characteristics of the experiences and perceptions of 56 design students, divided into 8 groups with students from three countries (Brazil, USA, Netherlands).

All students were exposed over 5 weeks, to the Sprint method of conception, this method popular in the day-by-day of multinational technology companies (KNAPP, 2016). This article brings positive evidence of performance and results from the use of this method in the classroom, with teams of multiple nationalities. However, this method applied in this context led all students involved in a feeling of lack of organization and communication gaps. It is worth 
exploring in similar events if this result was not due to the cultural characteristics of the countries involved.

The Brazilian students who participated in the activity, and had the mission to report the events through face-to-face and weekly mentoring, reported difficulties in understanding the linearity of the sprint method by students from other countries (USA, Netherlands), as well as an inclination of these students of the northern hemisphere, for design results that aimed at the graphics performance of the designer. However, all final results expressed high prototype quality, and all projects at a lower or higher level involved technologies, that is, they were delivered as digital services format.

The final results were considered very positive by the 3 universities and by the majority of the students. For the Brazilian students, the discipline of TGSA was very worthwhile in terms of contact with international students, different methodologies and contact with the English language. It is important to note that several problems were pointed out by the students, most of them agree that the difficulty of communication was the main difficulty, but that did not diminish the quality of the experience during the discipline. The problems raised by the students will be taken into account to the next subjects. In 2019.2 the discipline will be done in partnership with BUAS only. And in 2020.1 it will be possible to repeat the triple COIL - UFPE, BUAS and SUNY - of this semester.

It is encouraged here that similar experiences of students, teachers and other participants in such disciplines also share findings and details of similar events. In support of the enrichment of the literature on disciplines with total or partial collaboration remotely (different from EAD), and with multiple participants nationalities and cultures.

Some gaps have been mapped during this course and can be refined into future achievements. It is recommended that upcoming experiments and similar events build on success metrics, in relation to the student experience and output qualities, in a replicable way. Adding to the more pragmatic perspective of the situation.

Another possibility is to incorporate people from other design areas, such as artists, engineers, architects, and non-project areas into groups. In order to find performance changes with multidisciplinary groups. This variety of knowledge is a characteristic of project teams outside the educational environment. In addition to being multidisciplinary and interdisciplinary are estimated characteristics within the practice of design.

The list of opportunities is added to change the freedoms in relation to the final artifact produced, as well as to test other models of accompaniment and mentoring. These changes can have a positive impact on the quality of projects, and benefit in terms of knowledge and practical application in other design fields.

\section{References}

Hanington, Bruce; Martin, Bella. "Universal Methods of Design: 100 ways to Research Complex Problems, Develop Innovative Ideas, and Design Effective Solutions". Everley, MA, USA: Rockport, 2012.

Knapp, Jake; Keratsky, John; Kowitz, Braden. "Sprint: How To Solve Big Problems and Test New Ideas in Just Five Days". Bantam Press, 2016.

Lobach, Bernd. "Design Industrial: Bases Para a Configuração dos Produtos Industriais". Blucher, 1를 Edição, 1969.

Pazmino, Ana Veronica. "Como se cria". Blutcher, 2015.

Sutherland, Jeff; Sutherland, J.J . "Scrum: The Art of Doing Twice the Work in Half the Time".Crown Business, 2014. 
Neves, C.E., Campos, F.F.C., Dagui , G. \& Franklin, W.| The experience of design students during an international project cooperation

Thoring, Katja; Desmet, Pieter; Bandke-Schaub, Petra."Creative environments for design education and practice: A typology of creative spaces". Design Studies 56 (2018) 0142694X. Elsevier, 2018. https://doi.org/10.1016/j.destud.2018.02.00154

\section{Sobre o(a/s) autor(a/es)}

Cecília Eloy Neves, Mestranda, UFPE, Brazil <ceciliaeloyneves@gmail.com>

Fábio Ferreira da Costa Campos, PhD, UFPE, Brazil <fc2005@gmail.com>

Guilherme Daguir, Mestrando, UFPE, Brazil <gui.daquir@gmail.com>

Walter Franklin, PhD, UFPE, Brazil <ergonomia@gmail.com> 